Article

\title{
Hydrophobic Calcium Carbonate for Cement Surface
}

\author{
Shashi B. Atla ${ }^{1}$, Yi-Hsun Huang ${ }^{2}$, James Yang ${ }^{1}$, How-Ji Chen ${ }^{2,+}{ }^{*}$, Yi-Hao Kuo ${ }^{2}$, \\ Chun-Mei Hsu ${ }^{3}$, Wen-Chien Lee ${ }^{3}$, Chien-Cheng Chen ${ }^{4}$, Duen-Wei Hsu ${ }^{4}$ \\ and Chien-Yen Chen $1,+, *$ \\ 1 Department of Earth and Environmental Sciences, National Chung Cheng University, 168 University Road, \\ Minhsiung, Chiayi County 62102, Taiwan; shashi_org@yahoo.com (S.B.A.); chieyechen@yahoo.com (J.Y.) \\ 2 Department of Civil Engineering, National Chung Hsing University, 250 Kuo Kuang Road, \\ Taichung 4022, Taiwan; x699237014x@gmail.com (Y.-H.H.); yhkao31@gmail.com (Y.-H.K.) \\ 3 Department of Chemical Engineering, National Chung Cheng University, 168 University Road, Ming-Shung, \\ Chiayi County 62102, Taiwan; gupi_girl@livemail.tw (C.-M.H.); chmwcl@ccu.edu.tw (W.-C.L.) \\ 4 Department of Biotechnology, National Kaohsiung Normal University, No.62 Shenjhong Road, \\ Yanchao Township, Kaohsiung County 82444, Taiwan; cheng@nknu.edu.tw (C.-C.C.); \\ duenwei.hsu@gmail.com (D.-W.H.) \\ * Correspondence: hojichen@nchu.edu.tw (H.-J.C.); chien-yen.chen@oriel.oxon.org (C.-Y.C.); \\ Tel.: +886-5-2720411 (ext. 66220) (C.-Y.C.) \\ + These authors contributed equally to this work.
}

Academic Editor: Linda Pastero

Received: 14 November 2017; Accepted: 8 December 2017; Published: 11 December 2017

\begin{abstract}
This report describes a novel way to generate a highly effective hydrophobic cement surface via a carbonation route using sodium stearate. Carbonation reaction was carried out at different temperatures to investigate the hydrophobicity and morphology of the calcium carbonate formed with this process. With increasing temperatures, the particles changed from irregular shapes to more uniform rod-like structures and then aggregated to form a plate-like formation. The contact angle against water was found to increase with increasing temperature; after $90^{\circ} \mathrm{C}$ there was no further increase. The maximum contact angle of $129^{\circ}$ was obtained at the temperature of $60^{\circ} \mathrm{C}$. It was also found that carbonation increased the micro hardness of the cement material. The micro hardness was found to be dependent on the morphology of the $\mathrm{CaCO}_{3}$ particles. The rod like structures which caused increased mineral filler produced a material with enhanced strength. The ${ }^{13} \mathrm{C}$ cross polarization magic-angle spinning NMR spectra gave plausible explanation of the interaction of organic-inorganic moieties.
\end{abstract}

Keywords: SEM; X-ray diffraction; carbonation; micromechanics; $\mathrm{CaCO}_{3}$; cement

\section{Introduction}

Synthesis of organic-inorganic hybrids has received a great deal of attention in the field of material science [1] because it can result in the creation of multifunctional materials. The applications of hybrid organic-inorganic materials are found in various fields such as optics, electronics, energy, housing and the environment [2]. The desired function can be delivered from manipulating organic or inorganic or both components.

It is fair to say that modern civilizations have depended to a large degree on concrete material for the history of concrete usage, please see [3]. Various properties of concrete can be fabricated for specific applications. Concrete, however, is potentially vulnerable to a variety of different exposures unless some certain precautions are taken. Durability of concrete has serious economic implications in the form of maintenance and replacement costs of a structure. Therefore, in designing structures, the durability characteristics of the concrete should be evaluated as carefully as other aspects such 
as mechanical properties, hardness, and initial coast. Permeability is a determinant parameter that has the largest influence on the durability of concrete; the size and continuity of the pores in hydrated cement mortar would control the coefficient of permeability [4]. To decrease the permeability of concrete, the waterproofing treatment is recognized as an effective way. For waterproofing treatments, it requires the impregnation of concrete walls with hydrophobic agents. Hydrophobic treatment prevents wetting of the concrete's porous structure. A great number of organic additives have been studied as hydrophobic reagents including alkyl-alkoxy silane [5,6], surfactants [7,8], acrylic and polyurethane $[6,9]$. Concrete carbonation is a process in which carbondioxide reacts with calcium hydroxide [10-12] in the cement matrix to form calcium carbonate and water and the reaction stoichiometry is: $\mathrm{Ca}(\mathrm{OH})_{2}+\mathrm{CO}_{2} \rightarrow \mathrm{CaCO}_{3}+\mathrm{H}_{2} \mathrm{O}$.

There are many reports on the synthesis of hydrophobic calcium carbonate via carbonation route [13]. Hydrophobic calcium carbonate leads to many industrial applications. It is used as pigment, mortar, and abrasive and in paper and plastic as a filler [14]. Chen et al. have reported carbonation of $\mathrm{Ca}(\mathrm{OH})_{2}$ to synthesize cubic $\mathrm{CaCO}_{3}$ using dodecanoic acid as modifier [13]. Several organic additives used for synthesizing hydrophobic $\mathrm{CaCO}_{3}$ via carbonation of $\mathrm{Ca}(\mathrm{OH})_{2}$ include oleic acid [15], octadecyl dihydrogen phosphate [16], sodium oleate [17], stearic acid [18], and dodecanoic acid [19]. Various hydrophobic admixtures have been examined for concrete and mortar. In many cases the admixture caused damage, e.g., greater decay of samples in the frost resistance test. Some admixtures are effective, but their selection must be confirmed by further research $[20,21]$.

No study, however, has yet been reported on synthesis of hydrophobic cement surface material via carbonation route. For many years, metal soaps have been studied for the hydrophobic properties, but have not been used in hydrophobising building materials in practice [12]. This is because the by-products of the use of soaps are water-soluble salts that lead to increased hygroscopicity of the material [22]. In addition, it is not recommended to use soaps for the hydrophobising of building surfaces due to its low resistance to dirt, mechanical damage and salinity $[23,24]$. Another unfavorable factor includes interference with the cement hydration process in the presence of a hydrophobic compound that decreases the compressive strength of materials. Currently, only the organosilicon compounds are used for hydrophobisation concrete with Portland cement. However, the disadvantage of this hydrophobic cement is that it is very expensive $[21,25,26]$.

In this report we describe a feasible single step involving in situ synthesis of hydrophobic cement surface with stearic acid. We found that the temperature of carbonation reaction has a great deal of effect on morphology of $\mathrm{CaCO}_{3}$ and thus the hydrophobicity of the concrete surface. Furthermore, the carbonation and mineralization improved the surface micro hardness of the samples.

\section{Experimental Section}

Type I Portland cement based on ASTM C150 and Ottawa sand with the size distribution from $0.1 \mathrm{~mm}$ to $1 \mathrm{~mm}$ were used. A cement mortar was made from Portland cement with saturated surface dry sand, and tap water in the ratio of 4:11:2, and was cast into $2.5 \mathrm{~cm}$ cubes in an acrylic mold. The cubes were conserved at room temperature for a day and curing was done by continuous immersion in supersaturated solution of $\mathrm{Ca}(\mathrm{OH})_{2}$ for one week. The cement blocks were then taken for carbonation reaction. Carbonation reaction was done in an autoclave (Autoclave Engineers, $\mathrm{V}=500 \mathrm{~cm}^{3}$ ) at $\mathrm{CO}_{2}$ pressure of $2 \mathrm{kgf} / \mathrm{cm}^{2}$. The organic solution was prepared by taking 1:1 molar ratio ( 0.004 moles) of stearic acid and sodium hydroxide in $400 \mathrm{~mL}$ of deionized water. The mixture was stirred at $70{ }^{\circ} \mathrm{C}$ for $5 \mathrm{~min}$ and was filled so as to cover cubes in the autoclave. The autoclave was sealed and pressurized with $\mathrm{CO}_{2}$ to a desired pressure. The carbonation reaction was carried out at different temperatures $\left(30,60,90,120\right.$ and $\left.150^{\circ} \mathrm{C}\right)$ for a period of $24 \mathrm{~h}$. After this, the reactor was allowed to attain room temperature and $\mathrm{CO}_{2}$ gas was vented off, and the cubes were oven dried at $50{ }^{\circ} \mathrm{C}$ for one day. The cement cubes without organic solution and carbonation are referred to as "control experiments". The cement cubes with organic solution and without carbonation are referred to as "Ctrl-2 experiments". 
A small quantity of the material was scrapped from the cube surface and was characterized by XRD, IR and SEM. Powder X-ray diffraction (XRD) patterns were recorded on a Shimadzu X-ray diffractometer (LabX XRD-6000, Shimadzu, Tokyo, Japan) equipped with Ni-filtered CuK $\alpha(\lambda=0.1541 \mathrm{~nm}, 4 \mathrm{kVA}$, $30 \mathrm{~mA}$ ) radiation and a graphite crystal monochromator. SEM measurements were carried out on a Leica Stereoscan-440 scanning electron microscope (SEM, Leica, Cambridge, UK) equipped with a Phoenix EDAX attachment (Mahwah, NJ, USA). The water contact angles of the samples were measured using FTA 2000 contact angle goniometer (First Ten Angstroms, Portsmouth, VA, USA) by the sessile drop method using a micro syringe at $25^{\circ} \mathrm{C}$. FTIR spectra of the samples were recorded on a Shimadzu 8300 FTIR spectrometer (Shimadzu, Tokyo, Japan). Microhardness was measured using a micro-indentation tester (Shimadzu Micro Hardness Testers HMV-2, Shimadzu Corporation, Kyoto, Japan). The spectra of solid state NMR were performed using Bruker Avance III 400 NMR Spectrometer (Bruker, Billerica, MA, USA).

\section{Results and Discussion}

Figure 1 shows the XRD spectrum of the control and the carbonated cement cubes at different temperatures. The major peak of the controlled experiment were comprised of crystalline $\mathrm{SiO}_{2}$ diffraction signal value at $2 \theta=26.66^{\circ}$. It is well known that $\mathrm{SiO}_{2}$ is the common major constituent of the sand. On the other hand, XRD of the carbonated samples showed formation of a new peak at $2 \theta=29.32^{\circ}$, which corresponds to that of calcite peak $\left(\mathrm{CaCO}_{3}\right)$. Among the polymorphs of $\mathrm{CaCO}_{3}$ (calcite, aragonite, and vaterite), calcite is the thermodynamically stable phase under ambient conditions. This clearly indicates that carbonation has taken place in the materials undertaken for this study. Solid state ${ }^{13} \mathrm{C} C \mathrm{CP}-\mathrm{MAS}$ NMR also corroborates this and is discussed in the later section. Besides the peaks of $\mathrm{SiO}_{2}$ and $\mathrm{CaCO}_{3}$, few peaks at higher carbonation temperatures $\left(60\right.$ and $90{ }^{\circ} \mathrm{C}$ ) arise, which may be attributed to the association of organic molecule with the cement matrix to form calcium stearate. Ozturk et al. have reported the synthesis and X-ray diffraction of calcium stearate [27]. As per the synthesis procedure we synthesized $50 \%$ excess calcium stearate precipitate and obtained XRD spectrum which showed a high intensity diffraction peak at $2 \theta$ value of $19.96^{\circ}$. We assume small peaks near $20^{\circ}$ to be associated with calcium stearate in the cement matrix. Several typical vibrations bands of pure stearate molecules, including 2920, 2848 and $1463 \mathrm{~cm}^{-1}$ in the FTIR spectrum of stearate with different temperatures, are also observed (Figure S1).

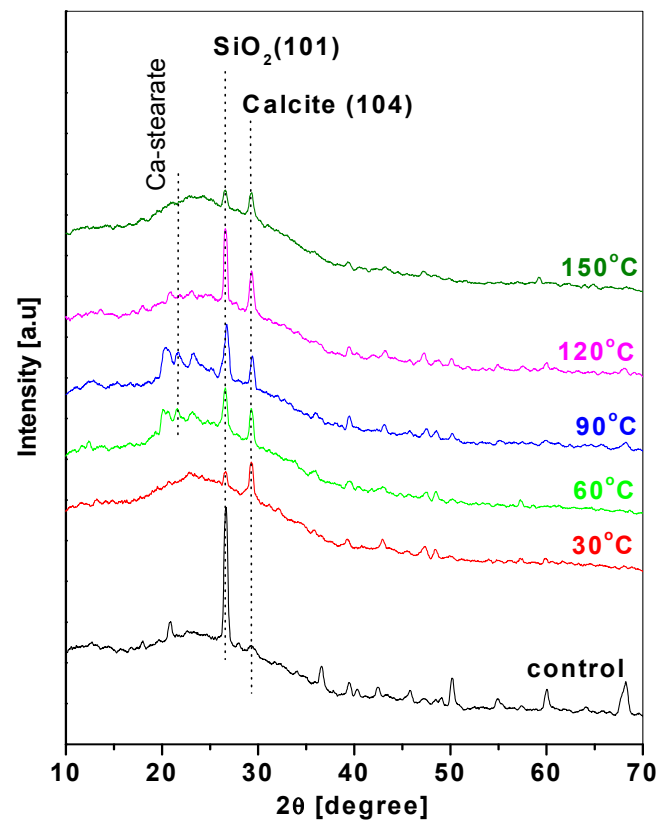

Figure 1. XRD pattern obtained from controlled and carbonated samples at different temperatures. 
Figure 2 shows the SEM images of the carbonated samples, which showed differences in particle morphology that were strongly dependent on carbonation reaction temperature. At $30^{\circ} \mathrm{C}$, the product has irregular morphology (flat surfaces). At temperatures of 60 and $90{ }^{\circ} \mathrm{C}$, these irregular particles transformed to form rod like structures and at higher temperatures of 120 and $150{ }^{\circ} \mathrm{C}$ the rod like structures transformed to aggregate particles (plate-like). The series of interactions between $\mathrm{Ca}(\mathrm{OH})_{2}$ in the cement matrix, stearic acid and $\mathrm{CO}_{2}$ varied with increasing carbonation reaction temperatures which gave rise to products with different morphology.

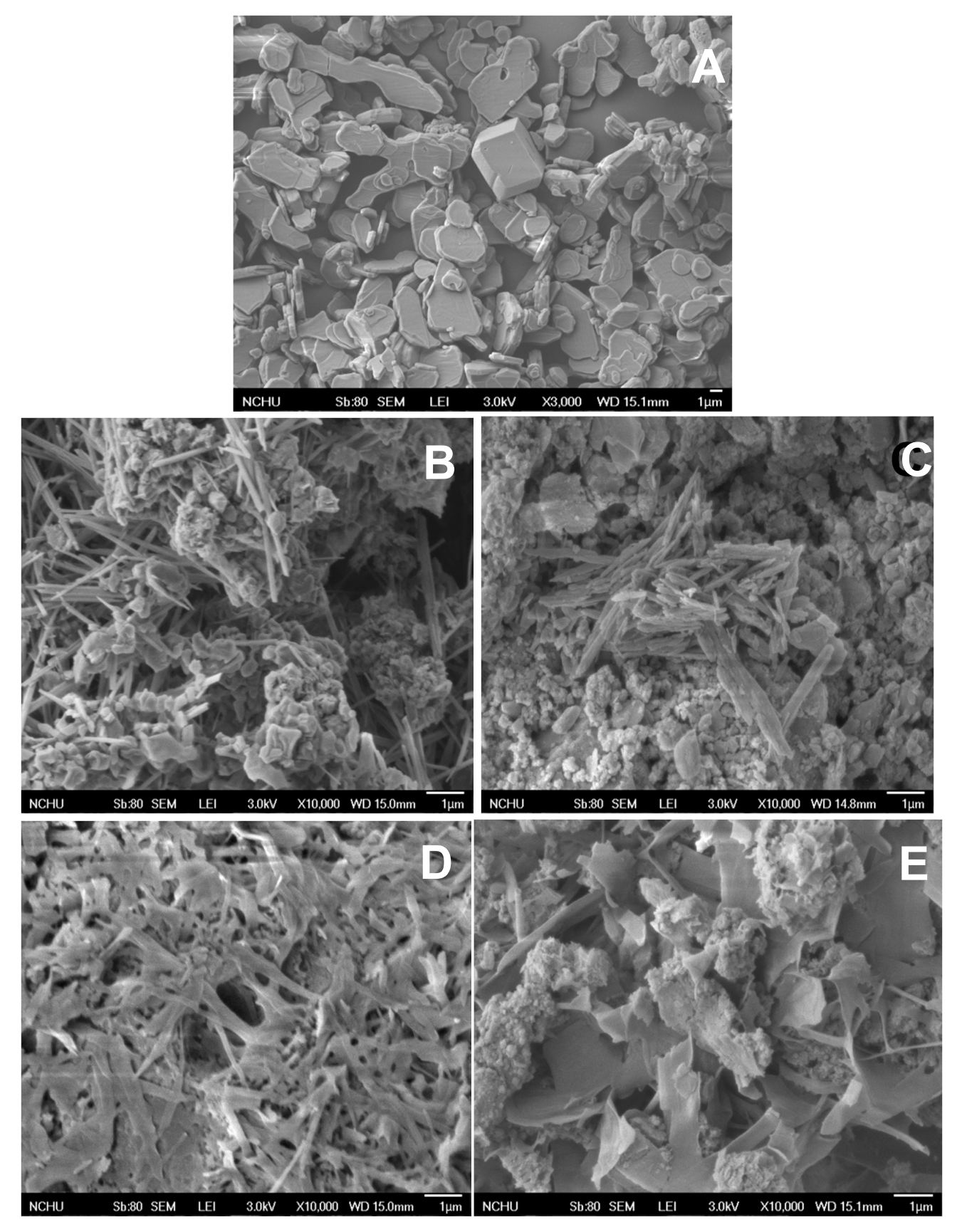

Figure 2. SEM images of the carbonated samples (A) $30^{\circ} \mathrm{C}$, (B) $60^{\circ} \mathrm{C},(\mathbf{C}) 90^{\circ} \mathrm{C},(\mathbf{D}) 120^{\circ} \mathrm{C},(\mathrm{E}) 150^{\circ} \mathrm{C}$.

The FTIR spectra of the carbonated samples showed (Figure 3) the characteristic peaks of calcium stearate. The interaction of $\mathrm{Ca}^{2+}$ and organic substrate with $\mathrm{COO}^{-}$functionality is already known in the literature [15]. Calcium stearate can be formed by the reaction of the $-\mathrm{COO}^{-}$of the stearic acid and $\mathrm{Ca}^{2+}$ ions to form a cover on the surface of $\mathrm{CaCO}_{3}$ particles. The peaks at 1577 and $1541 \mathrm{~cm}^{-1}$ 
are due to antisymmetric stretching bands for unidentate and bidentate association with calcium ions. The antisymmetric and symmetric methylene stretching were observed at 2916 and $2849 \mathrm{~cm}^{-1}$ respectively. These results are in agreement with functional groups present for calcium stearate [27]. The IR results showed that the intensity of $\mathrm{CH}_{2}$ stretching band increased initially for the temperatures from 30 to $90{ }^{\circ} \mathrm{C}$ and then decreased with further increase in temperature. This suggests that the surface modification of $\mathrm{CaCO}_{3}$ is reduced at higher temperatures.
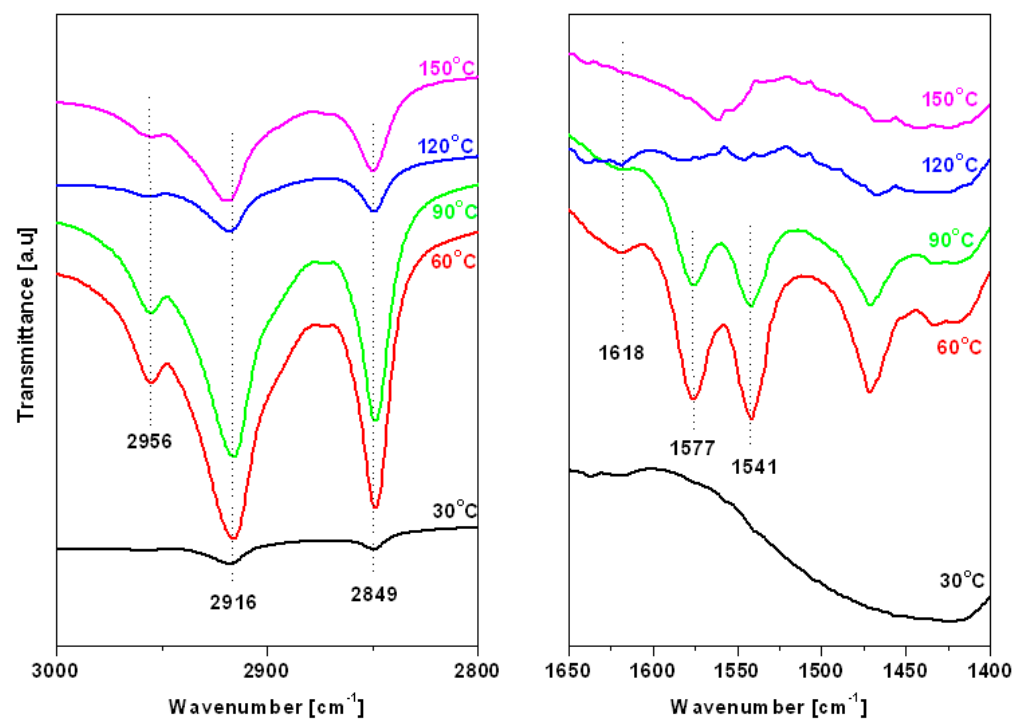

Figure 3. FTIR spectra of the carbonated samples at different temperatures.

In order to further investigate the structure elucidation of the synthesized samples, solid-state NMR spectroscopy was utilized in this study. Figure 4 presents the schematic of organic-inorganic interaction on the surface of the cement matrix. The $\mathrm{Ca}^{2+}$ reacts with $\mathrm{CH}_{3}\left(\mathrm{CH}_{2}\right)_{16} \mathrm{COO}^{-}$to form hydrophobic $\mathrm{Ca}\left(\mathrm{CH}_{3}\left(\mathrm{CH}_{2}\right)_{16} \mathrm{COO}\right)_{2}$, and thus formed $\mathrm{Ca}\left(\mathrm{CH}_{3}\left(\mathrm{CH}_{2}\right)_{16} \mathrm{COO}\right)_{2}$ are deposited on the $\mathrm{CaCO}_{3}$ precipitate formed during the carbonation of $\mathrm{Ca}(\mathrm{OH})_{2}$.
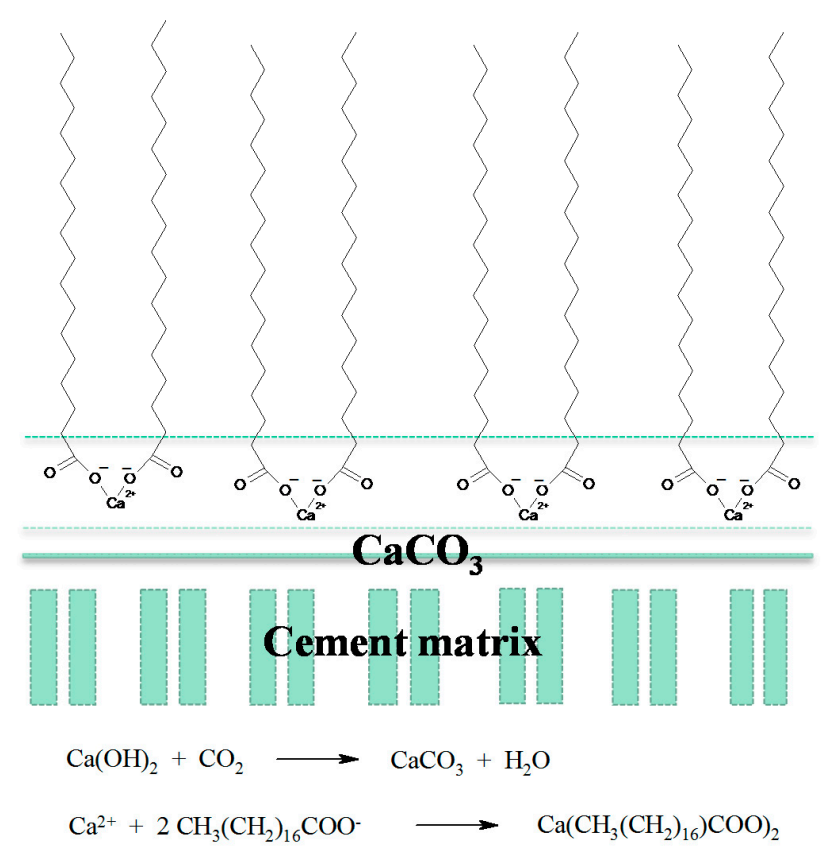

Figure 4. Schematic of the stearate molecules on $\mathrm{CaCO}_{3}$ in cement matrix. 
For NMR, samples obtained at $90{ }^{\circ} \mathrm{C}$ carbonation were used as a material for case study. Calcium stearate $(50 \%$ excess $\mathrm{Ca}$ ) were taken as reference material for comparing with the carbonated cement material. The solid state ${ }^{13} \mathrm{C}$ NMR spectras are presented in Figure 5. Figure 5a shows the NMR spectrum of pure calcium stearate. The carbonyl carbon (C1) signal exhibits at a resonance frequency of about $185.4 \mathrm{ppm}$ (normal stearic acid $\mathrm{C} 1$ position is at $179 \mathrm{ppm}$ [28]. The methyl $\left(\mathrm{CH}_{3}\right)$ and methylene $\left(\mathrm{CH}_{2}\right)$ group of calcium stearate resonates in the frequency range of $14.6-39.9 \mathrm{ppm}$. The high intensity peak at $33.05 \mathrm{ppm}$ is due to $\mathrm{CH}_{2}$ group (C4-C16) indicating their higher population of alkyl chain in the calcium stearate structure. The $\mathrm{C} 1, \mathrm{C} 2, \mathrm{C} 3, \mathrm{C} 17$, and $\mathrm{C} 18$ peaks are difficult to detect in the spectrum of cement block materials as compared to pure calcium stearate. Figure $5 \mathrm{~b}$ shows the carbonation of cement block without any sodium sterate, the formation of ${ }^{13} \mathrm{C}$ peak arises due to the formation of $\mathrm{CaCO}_{3}$ and its chemical shift value is 169.12 . This data clearly indicates that carbonation has taken place in our samples. Figure $5 \mathrm{c}$ shows the carbonation in the presence of sodium stearate. The presence of signal at chemical shift value of $33.5 \mathrm{ppm}$ can be attributed to the presence of stearate molecules, and the peak signal at $168.6 \mathrm{ppm}$ arises from $\mathrm{CaCO}_{3}$. There is slight change in peak value of $\mathrm{CH}_{2}$ group (C4-C16) after surface modification (33.5 ppm) as compared to pure calcium stearate (33.05 ppm). There is also a change in peak value of the corresponding ${ }^{13} \mathrm{C}$ peak of $\mathrm{CaCO}_{3}$ in the presence (168.6) of stearate molecules (absence 169.12). This upfield shift of $\mathrm{CaCO}_{3}$ arises due to shielding effect and clearly indicates surface modifications of cement blocks in the presence of stearate molecule. These studies also suggest plausible explanation of the organic-inorganic moieties interaction as shown in Figure 4.

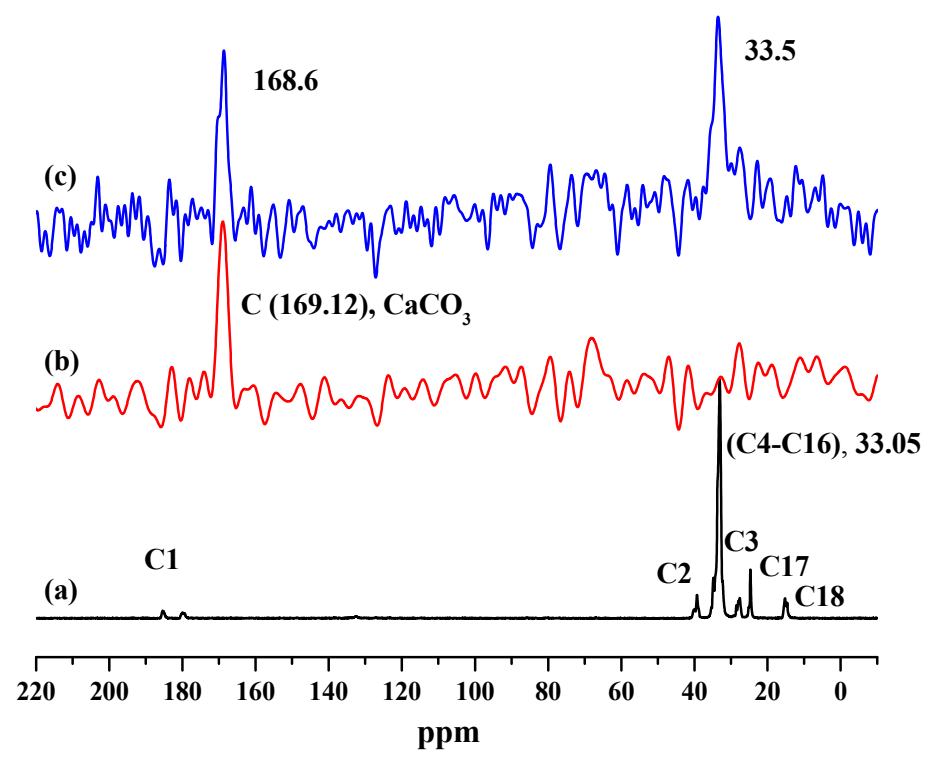

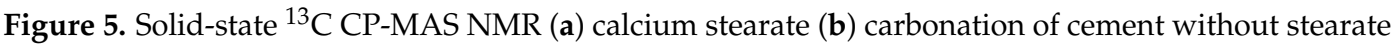
(c) carbonation in the presence of stearate.

The hydrophobic function is often demonstrated with water contact angle and is sometimes referred to as "lotus effect". Hydrophobicity is controlled both by hydrophobic substrate film and the roughness of the surface. To show the lotus effect, hydrophobicity as the basis for self-cleaning mechanism, the organic interaction characteristic of cement surface was measured by contact angle. The organic additive changes the property of concrete material in situ, Figures 6 and 7a show the contact angle of the cement surfaces obtained at different carbonation reaction temperatures. At lower reaction temperature $\left(30^{\circ} \mathrm{C}\right)$, the contact angle against the hydrophobized cement surface was zero. The contact angle increased to 129 and $125^{\circ}$ respectively for the temperatures 60 and $90^{\circ} \mathrm{C}$. Temperature increases the efficient interaction of stearate molecules and $\mathrm{Ca}^{2+}$ and $\mathrm{CO}_{3}{ }^{2-}$ inducing hydrophobic calcite hence an increment in the contact angle. However, further increase in temperature caused 
a slight decrease in the contact angle and remained constant after $90^{\circ} \mathrm{C}$. The surface roughness also seems to play an important role in enhancing or decreasing the hydrophobicity [29]. The results of IR and contact angle are in accordance with each other. On the other hand, contact angle of Ctrl-2 experiment at $90^{\circ} \mathrm{C}$ was found to be $\sim 80^{\circ}$ (other samples were not studied); this indicates that $\mathrm{CO}_{2}$ plays an important role in enhancing the hydrophobicity of the cement surface.

\begin{tabular}{|c|c|c|c|c|}
\hline sample & $1^{\text {st }}$ & $2^{\text {nd }}$ & $3^{\text {rd }}$ & $\begin{array}{l}\text { average water } \\
\text { contact angle }\end{array}$ \\
\hline $30^{\circ} \mathrm{C}$ & & & & $0^{\circ}$ \\
\hline $60^{\circ} \mathrm{C}$ & & & & $129^{\circ}$ \\
\hline $90^{\circ} \mathrm{C}$ & & & & $124.67^{\circ}$ \\
\hline $120^{\circ} \mathrm{C}$ & & & & $114.83^{\circ}$ \\
\hline $150^{\circ} \mathrm{C}$ & & & & $115.5^{\circ}$ \\
\hline
\end{tabular}

Figure 6. Water contact angle study on cement surfaces prepared by carbonation at different temperatures.

Micro structural features in cement systems such as porosity, pore structure, density, crystallinity and morphology, may affect the dependence of the fracture terms on microhardness. In our experiments, the micro hardness value first increases and then decreases with temperature as shown in Figure 7a. From SEM images, the rod like structures of $\mathrm{CaCO}_{3}$ at 60 and $90{ }^{\circ} \mathrm{C}$ caused increased calcite fiber mineral filler that bridged between cement particles, and thus they enhanced micro hardness of the interface. Microhardness of the carbonated samples was compared with that of the Ctrl-2 experiments as shown in Figure $7 \mathrm{~b}$. The carbonated samples showed higher microhardness of the cement surface, which was found to be dependent on the morphology of the carbonated samples.
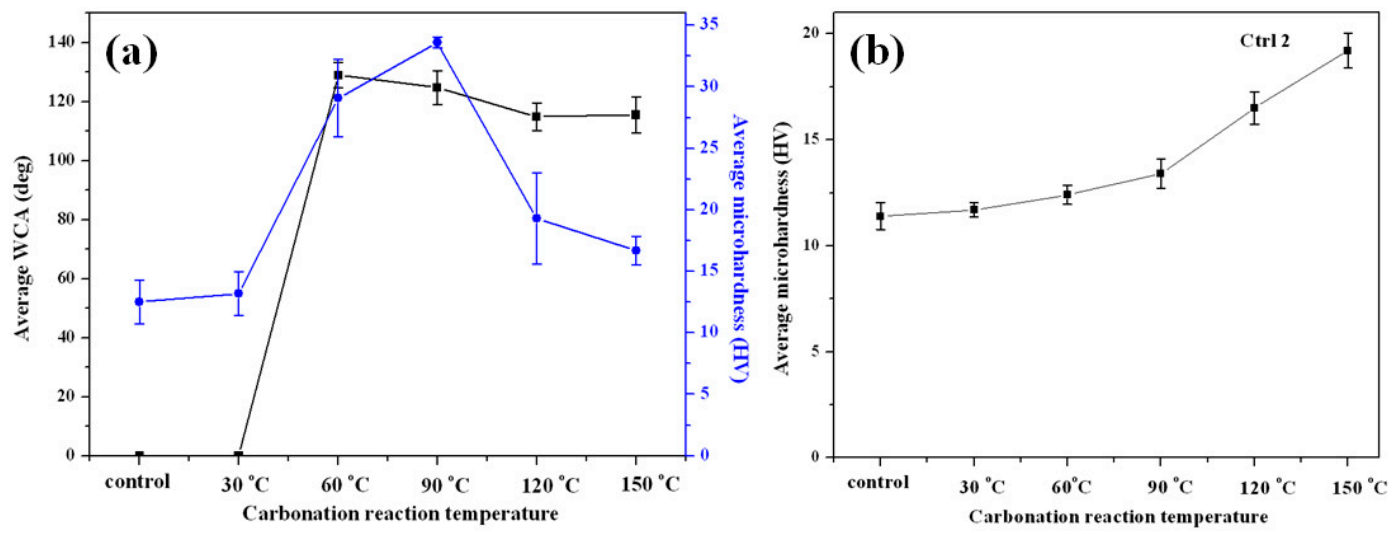

Figure 7. (a) Double $Y$ axis graph showing contact angle of the cement surface against water and micro hardness of cement blocks obtained at different carbonation reaction temperature; (b) microhardness of cement cubes of Ctrl 2 experiments. 


\section{Conclusions}

We have succeeded in obtaining hydrophobic cement surface via carbonation with the surface treatment with stearic acid in situ. The alkyl chain of stearic acid makes the $\mathrm{CaCO}_{3}$ hydrophobic. Our study showed that at carbonation temperatures of 60 and $90{ }^{\circ} \mathrm{C}$, maximum surface treatment with the stearic acid takes place as was seen from both the IR and contact angle. The different reaction temperature produced different morphology of the $\mathrm{CaCO}_{3}$ particles, and the rod like structures enhanced the microhardness of the samples. NMR studies also suggest the presence of organic-inorganic interactions. The synthesis of the hydrophobicity does not guarantee the effectiveness of the use of cement in concrete and construction. This is because the cement grains are surrounded by a hydrophobic coating, which makes it difficult or impossible to hydrate the cement. Hence, this leads to the decrease in compressive strength and the loss of sample mass after freezing-thawing [6]. Admixture hydrophobic creates chemical bonds between the individual components of concrete, affecting the changes in the microstructure, as well as changing the strength parameters [30]. The carbonation of cement surface seems to be a promising route to synthesize hydrophobic surface and its properties can be tailored by using different organic additives.

Supplementary Materials: The following are available online at www.mdpi.com/2073-4352/7/12/371/s1, Figure S1: FTIR spectrum of pure stearate stored at different temperatures.

Acknowledgments: The authors are very grateful to the Ministry of Science and Technology in Taiwan for sponsoring this research.

Author Contributions: James Yang, Yi-Hsun Huang and Chun-Mei Hsu conceived and designed the experiments; Yi-Hao Kuo and How-Ji Chen performed the experiments; Duen-Wei Hsu and Shashi B. Atla analyzed the data; Wen-Chien Lee contributed reagents/materials/analysis tools; Shashi B. Atla, Chien-Yen Chen and Chien-Cheng Chen wrote the paper.

Conflicts of Interest: The authors declare no conflict of interest.

\section{References}

1. Naka, K.; Chujo, Y. Control of Crystal Nucleation and Growth of Calcium Carbonate by Synthetic Substrates. Chem. Mater. 2001, 13, 3245-3259. [CrossRef]

2. Sanchez, C.; Belleville, P.; Popall, M.; Nicole, L. Applications of advanced hybrid organic-inorganic nanomaterials: From laboratory to market. Chem. Soc. Rev. 2011, 40, 696-753. [CrossRef] [PubMed]

3. Mindess, S.; Young, J.F.; Darwin, D. Concrete; Prentice Hall: Upper Saddle River, NJ, USA, 2003.

4. Monteiro, P.J.M.; Mehta, P.K. Concrete: Structure, Properties, and Materials; Prentice-Hall, Inc.: Upper Saddle River, NJ, USA, 1986.

5. Basheer, P.A.M.; Basheer, L.; Cleland, D.J.; Long, A.E. Surface treatments for concrete: Assessmentmethods and reported performance. Constr. Build. Mater. 1997, 11, 413-429. [CrossRef]

6. Tkach, E.V.; Semenov, V.S.; Tkach, S.A.; Rozovskaya, T.A. Highly Effective Water-repellent Concrete with Improved Physical and Technical Properties. Procedia Eng. 2015, 111, 763-769. [CrossRef]

7. Zhang, T.; Shang, S.; Yin, F.; Aishah, A.; Salmiah, A.; Ooi, T.L. Adsorptive behavior of surfactants on surface of Portland cement. Cem. Concr. Res. 2001, 31, 1009-1015. [CrossRef]

8. Maryoto, A. Resistance of Concrete with Calcium Stearate Due to Chloride Attack Tested by Accelerated Corrosion. Procedia Eng. 2017, 171, 511-516. [CrossRef]

9. Medeiros, M.H.F.; Helene, P. Surface treatment of reinforced concrete in marine environment: Influence on chloride diffusion coefficient and capillary water absorption. Constr. Build. Mater. 2009, 23, 1476-1484. [CrossRef]

10. Park, D.C. Carbonation of concrete in relation to $\mathrm{CO}_{2}$ permeability and degradation of coatings. Constr. Build. Mater. 2008, 22, 2260-2268. [CrossRef]

11. Izaguirre, A.; Lanas, J.; Álvarez, J.I. Effect of water-repellent admixtures on the behaviour of aerial lime-based mortars. Cem. Concr. Res. 2009, 39, 1095-1104. [CrossRef]

12. Maryoto, A. Improving Microstructures of Concrete Using $\mathrm{Ca}\left(\mathrm{C}_{18} \mathrm{H}_{35} \mathrm{O}_{2}\right)_{2}$. Procedia Eng. 2015, 125, 631-637. [CrossRef] 
13. Chen, Y.; Ji, X.; Zhao, G.; Wang, X. Facile preparation of cubic calcium carbonate nanoparticles with hydrophobic properties via a carbonation route. Powder Technol. 2010, 200, 144-148. [CrossRef]

14. Keum, D.-K.; Kim, K.-M.; Naka, K.; Chujo, Y. Preparation of hydrophobic $\mathrm{CaCO}_{3}$ composite particles by mineralization with sodium trisilanolate in a methanol solution. J. Mater. Chem. 2002, 12, 2449-2452. [CrossRef]

15. Wang, C.; Sheng, Y.; Hari, B.; Zhao, X.; Zhao, J.; Ma, X.; Wang, Z. A novel aqueous-phase route to synthesize hydrophobic $\mathrm{CaCO}_{3}$ particles in situ. Mater. Sci. Eng. C 2007, 27, 42-45. [CrossRef]

16. Wang, C.; Xiao, P.; Zhao, J.; Zhao, X.; Liu, Y.; Wang, Z. Biomimetic synthesis of hydrophobic calcium carbonate nanoparticles via a carbonation route. Powder Technol. 2006, 170, 31-35. [CrossRef]

17. Sheng, Y.; Zhou, B.; Wang, C.; Zhao, X.; Deng, Y.; Wang, Z. In situ preparation of hydrophobic $\mathrm{CaCO}_{3}$ in the presence of sodium oleate. Appl. Surf. Sci. 2006, 253, 1983-1987. [CrossRef]

18. Wang, C.; Sheng, Y.; Zhao, X.; Pan, Y.; Hari, B.; Wang, Z. Synthesis of hydrophobic $\mathrm{CaCO}_{3}$ nanoparticles. Mater. Lett. 2006, 60, 854-857. [CrossRef]

19. Wang, C.; Piao, C.; Zhai, X.; Hickman, F.N.; Li, J. Synthesis and characterization of hydrophobic calcium carbonate particles via a dodecanoic acid inducing process. Powder Technol. 2010, 198, 131-134. [CrossRef]

20. Jumate, E.; Manea, D.L.; Moldovan, D.; Fechete, R. The Effects of Hydrophobic Redispersibele Powder Polymer in Portland Cement Based Mortars. Procedia Eng. 2017, 181, 316-323. [CrossRef]

21. Falchi, L.; Zendri, E.; Müller, U.; Fontana, P. The influence of water-repellent admixtures on the behaviour and the effectiveness of Portland limestone cement mortars. Cem. Concr. Compos. 2015, 59, 107-118. [CrossRef]

22. Izaguirre, A.; Lanas, J.; Álvarez, J.I. Ageing of lime mortars with admixtures: Durability and strength assessment. Cem. Concr. Res. 2010, 40, 1081-1095. [CrossRef]

23. Maranhao, F.; John, V.; Loh, K.; Pileggi, R. The influence of silicone based water repellents as admixtures on the rheological properties of cement slurry. In Proceedings of the Hydrophobe V, 5th International Conference on Water Repellent Treatment of Building Materials, Brussels, Belgium, 15-16 April 2008; pp. 255-258.

24. Klisińska-Kopacz, A.; Tišlova, R. Effect of hydrophobization treatment on the hydration of repair Roman cement mortars. Constr. Build. Mater. 2012, 35, 735-740. [CrossRef]

25. Falchi, L.; Müller, U.; Fontana, P.; Izzo, F.C.; Zendri, E. Influence and effectiveness of water-repellent admixtures on pozzolana-lime mortars for restoration application. Constr. Build. Mater. 2013, 49, 272-280. [CrossRef]

26. Xue, X.; Li, Y.; Yang, Z.; He, Z.; Dai, J.-G.; Xu, L.; Zhang, W. A systematic investigation of the waterproofing performance and chloride resistance of a self-developed waterborne silane-based hydrophobic agent for mortar and concrete. Constr. Build. Mater. 2017, 155, 939-946. [CrossRef]

27. Gönen, M.; Öztürk, S.; Balköse, D.; Okur, S.; Ülkü, S. Preparation and Characterization of Calcium Stearate Powders and Films Prepared by Precipitation and Langmuir-Blodgett Techniques. Ind. Eng. Chem. Res. 2010, 49, 1732-1736. [CrossRef]

28. Cunningham, I.D.; Courtois, J.-P.; Danks, T.N.; Heyes, D.M.; Moreton, D.J.; Taylor, S.E. Synthesis and characterisation of calixarene-stabilised calcium carbonate overbased detergents. Colloids Surf. A Physicochem. Eng. Asp. 2003, 229, 137-147. [CrossRef]

29. Bhushan, B.; Jung, Y.C. Natural and biomimetic artificial surfaces for superhydrophobicity, self-cleaning, low adhesion, and drag reduction. Prog. Mater. Sci. 2011, 56, 1-108. [CrossRef]

30. Corinaldesi, V. Combined effect of expansive, shrinkage reducing and hydrophobic admixtures for durable self compacting concrete. Constr. Build. Mater. 2012, 36, 758-764. [CrossRef]

(C) 2017 by the authors. Licensee MDPI, Basel, Switzerland. This article is an open access article distributed under the terms and conditions of the Creative Commons Attribution (CC BY) license (http://creativecommons.org/licenses/by/4.0/). 